\title{
A Review Paper on CFD Simulation of Square Threaded \& Helical Twisted Pin Fin Arrays in a Rectangular Channel to Enhance Heat Transfer
}

\author{
Javed Siddiqui ${ }^{1}$, A.V Gadekar ${ }^{2}$ \\ ${ }^{1}$ Department of Mechanical Engineering, Faculty of Mahatma Gandhi Mission"s Polytechnic Institute, Maharashtra state board of technical \\ education, Aurangabad Maharashtra, 431003, India
}

${ }^{2}$ Professor, Mechanical Engineering Department Marathwada Institute of Technology Aurangabad, Maharashtra, 431028, India

\begin{abstract}
The present paper gives the review on CFD Simulation of Square Threaded \& Helical twisted pin fin arrays in a rectangular Channel to enhance Heat transfer. The variable parameters are arrangement and variable geometry (Square Threaded \& Helical twisted pin fin arrays) of pin fin arrays by using the transient single blow technique. The experiment covers the following range : Reynolds number 13,500-42,000, the clearance ratio $(\mathrm{C} / \mathrm{H}) 0,0.33$ and 1 , the inter-fin spacing ratio $(\mathrm{Sy} / \mathrm{D}) 1.208,1.524,1.944$ and 3.417. Correlations equations are develop for enchantment of thermal efficiency of three dimensional fluid flow. The experimental review shows that the modifications with inline and staggered arrangement and different geometries (Square Threaded \& Helical twisted pin fin arrays) may lead to heat transfer enhancement by increasing thermal efficiency. Nusselt number and Reynolds number are considered as performance parameters for the experiments. The thermal performance analysis is made under constant pumping power constraints. For higher thermal performance lower inter-fin distance ratio and clearance ratio and comparatively lower Reynolds number should be preferred for staggered arrangement and different geometry. The result of staggered configuration and different geometries are also compared with the result of inline arrangement and pin fins with cylindrical geometry.
\end{abstract}

Keywords: CFD Simulation, heat transfer enhancement, Square Threaded \& Helical twisted pin fin, staggered arrangement

\section{Introduction}

Heating of an element under various working applications is a major problem for today's engineering devices therefore rapid heat removal from heated surfaces and reducing material weight and cost has become a major task for design of heat exchanger equipments. Development of super heat exchanger requires fabrication of efficient design techniques to exchange great amount of heat between surfaces such as external surfaces and ambient fluid. Extended surfaces (fins) are widely used in heat exchanging devices for the purpose of increasing the heat transfer between a primary surface and the surrounding fluid. Various types of heat exchanger fins, ranging from relatively simple shapes, such as rectangular, square, cylindrical, annular, tapered, dropped shape or pin fins of different geometries have been used. One of the commonly used fins is the pin fin, these fins may protrude from either a rectangular or cylindrical base. A pin fin is a cylinder or other shaped element attached perpendicular to a wall with the transfer fluid passing in cross flow over the element. Pin fins having a height-to-diameter ratio, $\mathrm{H} / \mathrm{d}$, between 0.5 and 4 are accepted as short fins, whereas long pin fins have a pin height-to-diameter ratio, $\mathrm{H} / \mathrm{d}$, more than 4 . Short pin fins are widely used in the trailing edges of gasturbine blades, in electronic cooling equipments and in the aerospace industry. The large height-to-diameter ratio is of particular interest in heat-exchanger applications in which the attainment of a very high heat-transfer coefficient and pressure drop is of major concern. The relative fin height $(\mathrm{H} / \mathrm{d})$ affect the heat transfer of pin fins and other affecting factors include the velocity of fluid flow, the thermal properties of fluid, the cross sectional shape of pin fins like square threaded and helical twisted, the relative inter-fin pitch, the arrangement of pin fins like in-line, staggered arrangements.

This Study is aimed mainly at examining the CFD simulation for heat transfer enhancement from square threaded and helical twisted pin fins under inline and staggered arrangement which result of introducing body modification to the fin body. The modification in this work is a square threaded and helical twisted geometry made through the fin thickness of cylindrical pin fin. The CFD simulation study investigates the influence of body geometry on heat dissipation rate and pressure drop across the rectangular tunnel of the square threaded and helical twisted pin fins. The modified pin fin geometries are compared to the corresponding solid fins in terms of heat transfer rate and also comparing will be between all different geometries of fins.

\section{Nomenclature}

A Heat transfer area

Q Heat transfer rate

$\mathrm{T} \quad$ Steady-state temperature

$\mathrm{U}$ Mean velocity of the air

V Voltage

W Width of the base plate and the duct

$\Delta \mathrm{P}$ Pressure difference

$\mathrm{X} \quad$ Kinematic viscosity of air

D Diameter of the pins

Dh Hydraulic diameter of the duct

f Friction factor

h Heat transfer coefficient

$\mathrm{H} \quad$ Height of the fins

I Current 


\section{International Journal of Science and Research (IJSR) ISSN (Online): 2319-7064}

Index Copernicus Value (2013): 6.14 | Impact Factor (2014): 5.611

L Length of base plate

Lt Length of the test section

$\mathrm{k}$ Conductivity of air

$\mathrm{Np} \quad$ Number of the pin fins

$\mathrm{Nu}$ Nusselt number

$\mathrm{R} \quad$ Resistant of heater element

Re Reynolds number

Ts Surface Temperature

$\mathrm{h}_{\mathrm{av}} \quad$ Average heat transfer coefficient

$\mathrm{T}_{0} \quad$ Surrounding Temperature

As Heat Transfer Surface Area

$\mathrm{P}_{\mathrm{r}} \quad$ Prandtl number

$\rho \quad$ Density of air

Tm Mean Temperature

$\mathrm{Nu}_{\mathrm{s}} \quad$ Nusselt number of smooth surface

$\mathrm{Nu}_{\mathrm{t}} \quad$ Nusselt number of Total Area

$\mathrm{Nu}_{\mathrm{p}}$ Nusselt number of Projected Area

$h_{a} \quad$ Convective heat transfer Coefficient with fins

$\mathrm{h}_{\mathrm{s}} \quad$ Convective heat transfer Coefficient without fins

\section{Literature Survey}

There have been many investigations carried out for the heat transfer and pressure drop of rectangular channels with pin fins, which are restricted to pin fins with circular and square cross-sections. Sparrow and coworkers [15],[16] were investigate the heat transfer performance of inline and staggered pin fin arrays of cylindrical fins. Metzger et al. [6] investigated the effects of pin-fin shape and array orientation on the heat transfer and the pressure loss in pin-fin arrays. According to their results, the use of cylindrical pin-fins with an array orientation between staggered and in-line can sometimes promote the heat transfer, while substantially reducing pressure. When oblong pin-fins are used, heat transfer increases of around $20 \%$ over the circular pin-fins were measured, but these increases were offset by increases in the pressure loss of around $100 \%$. Their estimate indicated that the pin-fin surface coefficients were approximately double the end wall values.. Simoneau and Vanfossen [18] also studied the heat dissipation from a staggered array of cylindrical pin fins in a rectangular channel. Matsumoto et al. [19] studied the end wall heat transfer in the presence of inline and staggered adiabatic circular pin fins. A review of staggered array pin fin heat transfer for turbine cooling applications was presented by Armstrong and Winstanley [20]. Bayram Sahin, Alparslan Demir [2] studied the heat transfer enhancement and pressure drop over a flat surface equipped with square crosssectional and modification as perforated pin fins in a rectangular channel. The experimental results showed that the use of the square pin fins may lead to heat transfer enhancement and pressure drop over a flat surface. Enhancement efficiencies varied between 1.1 and 1.9 depending on the clearance ratio $(\mathrm{C} / \mathrm{H})$ and inter-fin spacing ratio(Sy/D). Both lower clearance ratio $(\mathrm{C} / \mathrm{H})$ and lower inter-fin spacing ratio(Sy/D) and comparatively lower Reynolds numbers are suggested for higher heat transfer enhancement. In this study, the overall heat transfer, friction factor and the effect of the various design parameters on the heat transfer for the heat exchanger equipped with square cross-sectional perforated pin fins were investigated experimentally. R. Karthikeyan, R. Rathnasamy [4] studied the heat transfer and friction characteristics of convective heat transfer through a rectangular channel with cylindrical and square cross-section pin-fins attached over a rectangular duralumin flat surface. The pin-fins were arranged in in-line and a staggered manner. Various clearance ratios $(\mathrm{C} / \mathrm{H}=0.0$, $0.5 \& 1.0)$ and inter-fin distance ratios (Sy/d and $\mathrm{Sx} / \mathrm{d})$ were used as a variable parameter. The experimental results showed that the use of square cross-section pin-fins may lead to an advantage on the basis of heat transfer enhancement and efficiency. For higher heat transfer enhancement, lower inter fin distance ratio and clearance ratio and comparatively lower Reynolds numbers should be preferred for in-line and staggered arrangement. The arrangement of staggered pin-fin array significantly enhanced heat transfer as a result turbulence at the expense of higher pressure drop in the wind tunnel. Square pin-fin array performance is slightly higher than the cylindrical array with the penalty of pressure drop. Tzer-Ming Jeng, Sheng-Chung Tzeng [23] studied the pressure drop and heat transfer of a square pin-fin array in a rectangular channel. The variable parameters are the relative longitudinal pitch $(\mathrm{XL}=1.5,2,2.8)$, the relative transverse pitch $(\mathrm{XT}=1.5,2$, 2.8 ) and the arrangement (in-line or staggered). The result shows that The in-line square pin-fin array has smaller pressure drop than the in-line circular pin-fin array at high $\mathrm{XT}(\mathrm{XT}=2.0$ or 2.8$)$ but an even slightly higher pressure drop at low XT (such as XT = 1.5). Additionally, the staggered square pin-fin array has the largest pressure drop of the three pin fin arrays (in-line circular pin-fins, in-line square pin-fins and staggered square pin-fins). Most in-line square pin-fin arrays have very low heat transfer than an inline circular pin-fin array, but a few, as when $\mathrm{XL}=2.8$, exhibit admirable heat transfer at high Reynolds number. For illustration, when $\mathrm{XL}=2.8, \mathrm{XT}=1.5$. Giovanni Tanda [6] studied Heat transfer and pressure drop experiments were performed for a rectangular wind tunnel equipped with fin arrays of diamond-shaped elements. Both in-line and staggered fin arrays were considered, for values of the longitudinal and transverse spacing's, relative to the diamond side, from 4 to 8 and from 4 to 8.5 , correspondingly. The height-to-side ratio of the diamonds was 4 . Thermal performance comparisons with data for a rectangular channel without fins showed that the presence of the diamond-shaped elements superior heat transfer by a factor of up to 4.4 for equal mass flow rate and by a factor of up to 1.65 for equivalent pumping power. G.J.Vanfossen and B.A.Brigham [7] deliberate the heat transfer by short pin-fins in staggered arrangements. According to their results, longer pin-fins transfer more heat than shorter pinfins and the array-averaged heat transfer with eight rows of pin-fins slightly exceeds that with only four rows. Their results also recognized that the average heat transfer coefficient on the pin surface is around 35\% larger than that on the end walls.

Okamoto et al. [24] considered the flow field in a matrix of surface mounted square blocks with width $\mathrm{D}=23 \mathrm{~mm}$ and height $\mathrm{H}=5 \mathrm{~mm}$ placed in a boundary layer. The face to face distance $\mathrm{S}$ was varied as $\mathrm{S} / \mathrm{H}=2,3,5,7,10$ and 13 in both streamwise and spanwise direction. The study showed that for $\mathrm{S} / \mathrm{H}<5$ the flow did not reattach at the channel floor and that the inter-obstacle space was fully covered by a large flow recirculation. Zukauskas and Ulinskas [25] studied interesting correlations between heat transfer and pressure

\section{Volume 4 Issue 12, December 2015}




\section{International Journal of Science and Research (IJSR) \\ ISSN (Online): 2319-7064 \\ Index Copernicus Value (2013): 6.14 | Impact Factor (2014): 5.611}

drop for in-line and staggered banks of tubes over wide ranges of Reynolds numbers and relative transverse and longitudinal pitches. Armstrong and Winstanley [22] reviewed how pin fin height $(\mathrm{H})$ and inter-fin pitch affect heat transfer and flow friction, as well as the effect of accelerating flow in converging pin-fin channels. Jubran et al. [26] establish that the optimal inter-fin pitch in both transverse and longitudinal directions was 2.5 times the diameter of the pin-fin, individually of both the arrangement of the pin-fins and the shroud clearance. Tahat et al. [27,28] discovered that, for in-line and staggered arrays, the ratios of the optimal transverse and longitudinal pitches to the pin-fin diameter required to make the most of the heat transfer from the pin-fin assembly, were 1.3 and 2.2, respectively. Babus ${ }^{\text {Haq }}$ et al. [29] reported that the optimal ratio of the inter-fin pitch to the pin fin diameter in the transverse direction was 2.04 for all pin-fin Experiments. However, the optimal ratios in the longitudinal direction were $1.63,1.71$ and 1.95 for poly tetra fluoro ethene pin-fins $(\mathrm{k}=1.7 \mathrm{~W} / \mathrm{m}$ C), mild-steel pin-fins $\left(\mathrm{k}=54 \mathrm{~W} / \mathrm{m} \_\mathrm{C}\right)$ and duralumin pinfins $\left(\mathrm{k}=168 \mathrm{~W} / \mathrm{m}_{-} \mathrm{C}\right)$, respectively. Notably, the optimal inter-fin pitches [26-29] are determined by the assembly of the channel and the base of the pin-fin array. Restated, for the test cases with small ratios of the transverse pitch to the pin-fin diameter, the distance from the base of the pin-fin array to the sidewall of the channel significantly improves the inter-fin space [26-29].

Grannis and Sparrow [30] used the distinctive experiments to confirm the accuracy of the numerical simulation of fluid flow through a diamond-shaped pin-fin array. They provided the correlation between the friction factor and the Reynolds number based on the results of numerical calculations. You and Chang [31,32] adopted experimental data to elucidate numerically the fluid flow and heat transfer characteristics of square pin-fin arrays that are fully restricted in a rectangular channel. Kim and Kuznetsov [33], and Kim et al. [34] modeled pin-fin heat sinks as porous media and examined their fluid flow and heat transfer analysis in a jet impinging channel and a cross-flow channel, respectively. Saha and Acharya [35] numerically deliberate flow and heat transfer in a periodic array of cubic pin-fins housed inside a channel. The pin-fins are arranged in an in-line pattern with both stream wise and transverse periodicity set to 2.5 times the pin-fin measurement. Three dimensional computations and unsteady $\mathrm{k}-\mathrm{e}$ turbulence model were employed in their work. Most of them listening carefully on the pin-fin array with the in-line arrangement and uniform distribution (meaning that the transverse pitch equaled the longitudinal pitch); they did not consider an array with non-uniform distribution. Sara et al. [36] also studied the pressure drop and the transfer of heat in rectangular channels with square pin-fins in in-line arrangements. They measured fixed transverse pitch but variable longitudinal pitch. Square pinfins in staggered arrangements have infrequently been investigated, and only Sara [37] investigated heat transfer on large relative pitches.

Jinn Foo and Chee Seng Tan, [38] investigated experimentally the use of staggered perforated pin fins to improve the rate of heat transfer although subject to an vertical impinging flow, International Journal of mechanical computational and manufacturing research, 1, pp. 56-61. Chamoli, et al, [39] worked on CFD to examine the heat transfer and friction loss characteristics in a horizontal rectangular channel having attachments of circular geometry fins over one of its heated surfaces. Baruah, et al, [40] worked on CFD to investigate heat transfer and pressure drop characteristics of elliptical pin fins in rectangular channel in a staggered arrangement. They found that perforated elliptical pin fins perform better than the solid elliptical pin fin. Wadhah, [41] experimentally investigated enhancement of natural convection heat transfer from the rectangular fins by geometry like circular perforations and showed that the heat transfer rate and the coefficient of heat transfer increases with increased number of perforation geometry. From the literature survey it has been observed that the majority of the parameters affecting the heat transfer and pressure drop processes were studied, but none emphasized the experimental investigation of lateral perforated fins with higher Reynolds number, for the reason that it requires vast number of experimentation, which enormously increases the experimental cost and period. One more restriction for the study is lack of experimentation in the forced convection. Baruah, A. Dewan and P. Mahanta, [42] Performance of elliptical pin fin heat exchanger model with three elliptical perforation geometries, CFD letters, 3, pp. 65-73. Wadhah Hussein Abdul Razzaq AI-Doori, [43] Enhancement of natural convection heat transfer from the rectangular fins by geometries like circular perforations, International journal of automotive and mechanical engineering, 4, , pp. 428-436

\section{Experimental Scheme}

\subsection{Experimental Set Up}


International Journal of Science and Research (IJSR)

ISSN (Online): 2319-7064

Index Copernicus Value (2013): 6.14 | Impact Factor (2014): 5.611

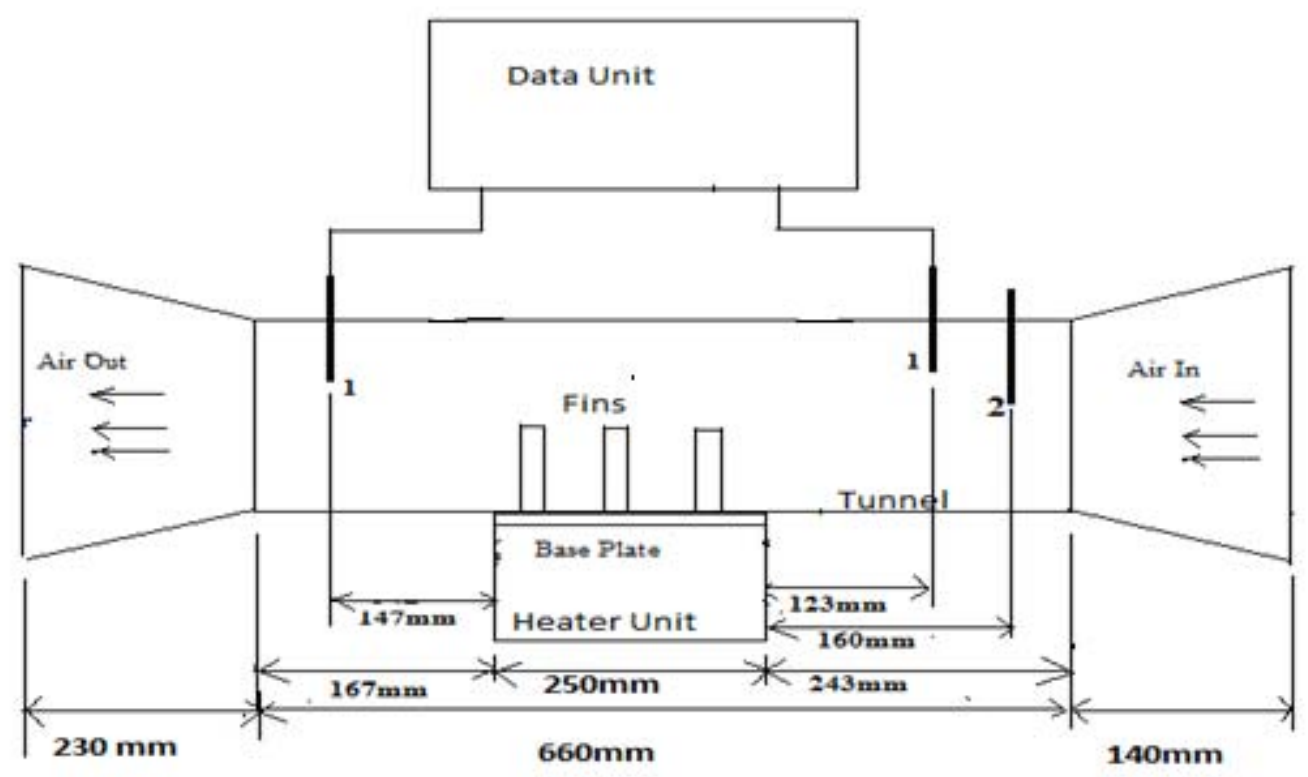

Figure 1: Experimental Set Up

The parts of Experimental set-up

1) Rectangular Tunnel

2) Heater

3) Test Plate

4) Computerized Data Collection Unit

\section{1) Rectangular Tunnel}

Rectangular tunnel is made up of wood having a thickness of $20 \mathrm{~mm}$, had an internal cross-section of $250 \mathrm{~mm} \times 100$ $\mathrm{mm}$. The total length of the channel is $1000 \mathrm{~mm}$. Rectangular tunnel will be operated in force draught mode by the blower of 0.5 H.P., 0 to $13000 \mathrm{rpm}, 220 \mathrm{~W}, 1.8 \mathrm{Kg}$, variable speed 1 to 6 and Blower will be operated at $45 \mathrm{~cm}$ height from the tunnel i.e. It was operated in suction mode and positioned horizontally. Blower has convergent and divergent section at both ends consisting of $30^{\circ}$ of inclination. To measure the mean inlet velocities of the air flow entering to the test section a Matrix anemometer is mounted in a tunnel. The range of this anemometer is 0 to $40 \mathrm{~m} / \mathrm{sec}$. The Reynolds number range used in this experiment was $13,500-42,000$, which is based on the hydraulic diameter of the channel over the test section $(\mathrm{Dh}=142.85 \mathrm{~mm})$ and the average velocity $(\mathrm{U})$. The outside area of the test section was coated with a film of glass wool insulation to obtained well insulation against thermal losses by conduction and convection to the surrounding atmosphere.

\section{2) Heater}

Heater has a square cross-section of $250 \mathrm{~mm}$ x $250 \mathrm{~mm}$; An assembly of test section is mounted in a square wooden box of dimension $270 \times 270 \mathrm{~mm}$ in which electrical heater placed between two M.S. Plate having the same dimension of base plate, a two firebrick of 250x $220 \mathrm{~mm}$. Dimensions of the electrical heater placed on the firebrick are $250 \mathrm{~mm} x$ $250 \mathrm{~mm}$. The heater output has a power of $200 \mathrm{~W}$ at $220 \mathrm{~V}$ and a current of $10 \mathrm{amp}$. To obtain a constant heat flux along the test plate the heater will be controlled by a variac transformer.

\section{3) Test Plate}

The square test plate is placed at base having the dimension $250 \mathrm{~mm} \times 250 \mathrm{~mm}$. The thickness of test plate is $6 \mathrm{~mm}$. The material used for pin fins and test plate is Aluminum because of the considering factors like high conductivity, good machinability and low cost. Some aluminum base plate is made without fins, some are of different geometrical perforated fins and some are of solid fins with inline and staggered arrangements. The circular cross section of fins is $15 \mathrm{~mm} \times 15 \mathrm{~mm}$ and they are attached on the upper surface of the test plate. Circular pin fins with different lengths, corresponding to $\mathrm{C} / \mathrm{H}$ (Clearance ratio) values of $0,0.333$ and 1 , are perforated at the $18 \mathrm{~mm}$ from bottom tip of those by an $9 \mathrm{~mm}$ diameter drill bit. The pin fins are fixed uniformly on the base plate with a constant spacing between the span wise directions of $18.125 \mathrm{~mm}$, with different spacing between the pin fins in the stream wise direction. The spacing ratios of the pin fins in the stream wise direction (Sy/D) were 1.208, 1.524, 1.944 and $3.417 \mathrm{~mm}$, giving different numbers of the pin fins on the base plate. As research shows that if the inter-fin spacing in the span wise direction decreases, the flow blockage will increase and it results into pressure drop along to tested heat exchanger will increase. The Test plate temperature is measured by RTD Sensors which can sense the temperature from range $0^{\circ} \mathrm{c}$ to $450^{\circ} \mathrm{c}$ and it is fitted into groove in the test plate the readings of the RTD Sensors will be shown on Computerized Data Collection Unit.

\section{4) Computerized Data Collection Unit}

Computerized Data Collection Unit consist of various indicating devices located on top which indicates the reading taken by the various component like RTD sensors to measure the temperature and Anemometer to measure air flow. There are three Temperature indicator among which two of them are located at inlet and outlet of test section. The third temperature indicator gives the temperature of base plate and maintains the temperature of base plate above safe value. To measure the Inlet flow rate of air is indicated by velocity indicator using Anemometer. Some safety

\section{Volume 4 Issue 12, December 2015}




\section{International Journal of Science and Research (IJSR) \\ ISSN (Online): 2319-7064 \\ Index Copernicus Value (2013): 6.14 | Impact Factor (2014): 5.611}

equipments are provided on data collection unit to avoid any type of accidents during any short circuit.

\subsection{Pin Fin Geometry}

A circular pin, Square Threaded \& Helical twisted pin fin are designed and test will be conduct in the current study. The pins all have the same cross-sectional area. The diameter of the circular pin is $15 \mathrm{~mm}$. The Square Threaded pin has a major diameter $15 \mathrm{~mm}$ and core diameter $9 \mathrm{~mm}$ and pitch $6 \mathrm{~mm}$ ( $3 \times 3 \mathrm{~mm}$ square thread) with different Sy/D ratio. Figure 2 shows Square Threaded pins: Square threadA, Square thread -B, and Square thread -C. Their lengths are 100,75 , and $50 \mathrm{~mm}$, respectively. Helical twisted pin fin has a diameter of $15 \mathrm{~mm}$ with helix angle of $400^{\circ}$ with different Sy/D ratio. Figure 2 shows Helical twisted pin fin: Helical twisted-D, Helical twisted -E, and Helical twisted -F. Their lengths are 100, 75, and $50 \mathrm{~mm}$, respectively.

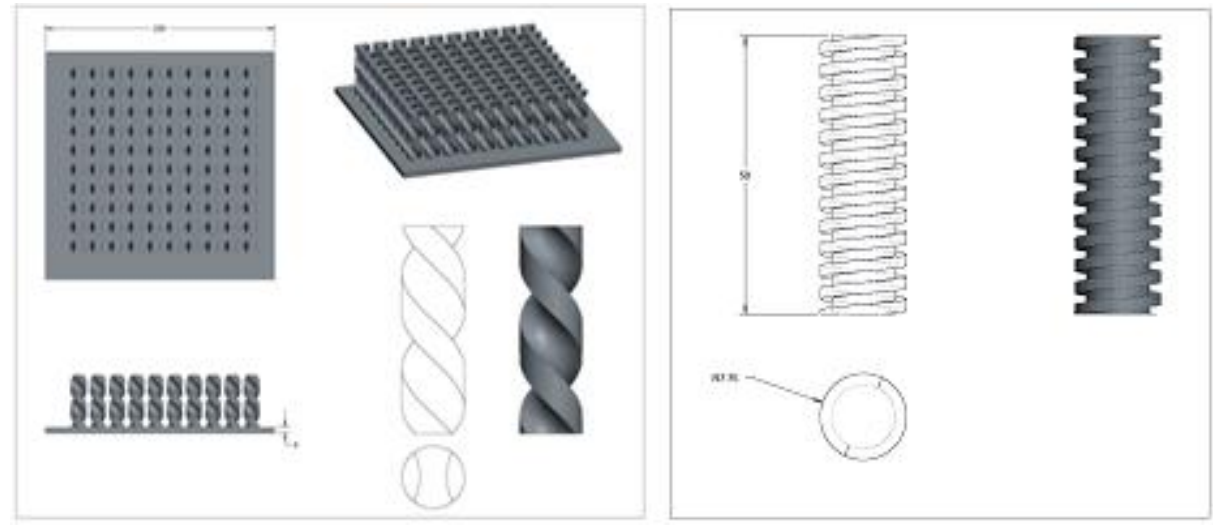

Figure 2: Pin Fin Geometry

Table 1: Details of Dimensions and Number of Base plate and Fins

\begin{tabular}{|c|c|c|c|}
\hline Sr. No & Particular & Size & Quantity \\
\hline 1 & Base Plate (without fins) & $250 \times 250 \mathrm{~mm}$ & 1 \\
\hline 2 & Base Plate (with fins) & $250 \times 250 \mathrm{~mm}$ & 12 \\
\hline 3 & Square threaded fin & $100 \mathrm{~mm}$ & 100 \\
\hline 4 & Square threaded fin & $75 \mathrm{~mm}$ & 25 \\
\hline 5 & Square threaded fin & $50 \mathrm{~mm}$ & 25 \\
\hline 6 & Helical twisted fin & $100 \mathrm{~mm}$ & 100 \\
\hline 7 & Helical twisted fin & $75 \mathrm{~mm}$ & 25 \\
\hline 8 & Helical twisted fin & $50 \mathrm{~mm}$ & 25 \\
\hline 9 & Solid pin fin & $100 \mathrm{~mm}$ & 100 \\
\hline 10 & Solid pin fin & $75 \mathrm{~mm}$ & 25 \\
\hline 11 & Solid pin fin & $50 \mathrm{~mm}$ & 25 \\
\hline
\end{tabular}

\section{Computation Scheme}

\subsection{Computational Domain}

The physical model of the project is built according to the experimental model. It will consist of three different sections viz. inlet section, test section, and exit section. The fluid and pin fins were modeled as a ,conjugated ${ }^{\text {ee }}$ computational domain to solve the problem. To calculate the reading the pin fin cross section in the stream wise directions will be modeled, and applied to the domain boundary. The boundaries are summarized as follows: Inlet: The flow temperature (Tin) will set to atmospheric temperature $303 \mathrm{~K}$ to be consistent with the experimental case, and the inlet velocity (uin) will be determined by the chosen Reynolds number. A turbulence intensity of $1 \%$ and turbulence length scale of $3 \%$ for the inlet height can be used. Walls conditions: The no-slip condition can apply to all the solid walls. An adiabatic thermal condition is applied to the end walls, and a constant heat flux condition is applied to the heated sidewalls of the tunnel. Symmetry planes :The symmetry planes can assumed to be modeled with zero heat flux. The mid- height plane is given zero velocity in the $\mathrm{z}$ direction and the mid-width plane is given a zero velocity in the $y$ direction $\left(u y^{1 / 40}\right)$; this disallowed the flow from crossing the boundary yet permissible a velocity profile to develop. Pins: The pin is treated as a solid volume with a constant thermal conductivity of $15 \mathrm{~W} /\left(\mathrm{m}_{-} \mathrm{K}\right)$. The pins are therefore assumed to be conjugated with the fluid. The noslip condition is functional to the pin surfaces. Outlet: The derivations of all the variables along the stream wise direction is situate to zero.[13]

\subsection{Numerical Mesh}

An unstructured grid arrangement is working in this study to meet the complex internal configuration of a channel implanted with pin fin arrays. Meshing is refined in some serious areas to ensure coverage for acceptable resolution: near the no-slip walls where velocity and temperature gradients are anticipated to be high and between the pins to confine the flow acceleration due to the decrease in crosssectional area. Approximately 650,000 computational grids are concerned in the entire computational domain and about 2000 grids in each pin fin. A run is considered to be gridindependent, if the overall heat transfer rate difference among the two remained below $2 \%$.[13]

\subsection{Computational Approach}

Three-dimensional numerical simulation will perform using ANSYS Fluent-CFD software. First-order up wind is to be select for the discreteness of the governing equations, and the standard $\mathrm{k}-\mathrm{e}$ turbulence model can be functional. It is compulsory to control the speed of calculation through under-relaxation [13]. Convergence is considered to be achieved when both of the subsequent criteria are met:(a)a reduction in all residuals of five orders in magnitude and (b) no observable change in the futuristic surface temperature for an additional 50 iterations. More details on these solvers can be establish in the ANSYS Fluent Software User"es 


\section{International Journal of Science and Research (IJSR)}

ISSN (Online): 2319-7064

Index Copernicus Value (2013): 6.14 | Impact Factor (2014): 5.611

Guide [44]

\section{Parameters and Data Treatment}

\subsection{Experimentation Methodology}

Governing Equations:

To find out the convective heat transfer rate "Q" from Electrical Heated Surface following equation were used.

$$
\mathrm{Q}_{\text {conv }}=\mathrm{Q}_{\text {elect }}-\mathrm{Q}_{\text {cond }}-\mathrm{Q}_{\text {rad }}
$$

Where "Q" denotes the heat transfer rate in which subscripts conv, elect, cond and rad denote convection, electrical, conduction and radiation, respectively.

The electrical heat input to heater is calculated from the electrical potential (V) and current(I) supplied to the surface.

$$
Q_{\text {elect }}=I^{2} \times R
$$

Where "I" is current flowing through the heater element and " $\mathrm{R}$ " is the resistance to flow.

The two sides walls and the top wall of the test section are well insulated against temperature difference and readings of the thermocouple placed at the inlet of tunnel should be nearly equal to ambient temperature, one could assume with some confidence that the last two terms of Eq.(1) may be ignored.

Investigation of projects reported that total heat loss due to radiation from test surface would be about $0.5 \%$ of the total electrical heat input given to the heater. The heat losses due to conduction through the sidewalls can be ignored in comparison to those through the bottom surface of the test section as it is supplied with exterior heater. By using these conclusion, jointly with the reality that the two sides walls and the top wall of the test section of tunnel are well insulated and readings of the thermocouple placed at the inlet of tunnel should be almost equal to ambient temperature, therefore one could guess with some confidence that the heat transfer due to the conduction and radiation may be unnoticed.

The heat transfer from the test section by convection can be expressed as

$$
\mathrm{Q}_{\text {conv }}=\text { hav As }\left[\text { Ts }-\frac{(\text { Tout }- \text { Tin })}{2}\right]
$$

Therefore average Convective Heat Transfer Coefficient $\left(\mathrm{h}_{\mathrm{av}}\right)$ can be determined as

$$
\mathrm{h}_{\mathrm{av}}=\frac{\mathrm{Q} \operatorname{conv}}{\operatorname{As}[\mathrm{Ts}-(\text { Tout }-\operatorname{Tin}) / 2]}
$$

For the calculation purpose Either the projected or the total area of the test surface can be in use as the heat transfer surface area. The total designed area is equal to the sum of the projected area and surface area contribution from the pin fins. Both these two areas can be associated to each other as

Total area $=$ Projected area + Total surface area contribution from the blocks

$\mathrm{As}=\mathrm{WL}+[\pi \mathrm{DH}] \mathrm{Np}$ For Solid Fins where ", $\mathrm{W}^{\mathrm{ee}}$ is the width of the base plate, , $\mathrm{L}^{\mathrm{ce}}$ its length of base plate, ,Np $\mathrm{Ne}^{e e}$ is the number of fins, , $\mathrm{H}^{e e}$ the height of fin and" $\mathrm{D}^{\text {ee }}$ is the diameter of the fins.

The dimensionless groups are calculated as follows:

$$
\mathrm{Nu}=\frac{\text { haVDh }}{\mathrm{K}}
$$

Nusselt number based on the projected area will replicate the effect of the difference in the surface area as well as that of the disturbances in the flow due to fins on the heat transfer. But $\mathrm{Nu}$ based on the total area will reflect the result of the flow disturbances only. In this study, heat transfer improvement Characteristics can be determined by using $\mathrm{Nu}$-based projected area.

The hydraulic diameter is defined as the ratio of the open duct volume existing for flow to the total wetted surface area inside the pin fin array region. This ratio is the most suitable characteristic length because it is representative of the different configurations investigated in this study and captures the influence of all the length scales in the problem.

$$
\mathrm{D}_{\mathrm{h}}=\frac{4 \mathrm{Vf}}{\text { Af }}
$$

where $\mathrm{Vf}$ is the entire fluid volume inside the pin fins array area. Af is the wetted surface area, which is defined as the total convective heat transfer area in contact with the flowing fluid. The total convective heat transfer area includes the wall and pin areas get in touch with the fluid.

For a rectangular duct with width $\mathrm{B}$ and height $\mathrm{H}$, pin with section area AP and circumference length Lp, number of pin fins $\mathrm{Np}$, and length of pin fin array in the stream wise direction $\mathrm{L}$

$\mathrm{V}_{\mathrm{f}}=\mathrm{BHL}-\mathrm{NpA}_{\mathrm{p}} \mathrm{H}$

$A_{f}=2(B+H) L+N p\left(L_{p} H-2 A_{p}\right)$

The Reynolds number is defined based on the hydraulic diameter as.

$$
\mathrm{R}_{\mathrm{e}}=\frac{\mathrm{Umax} \mathrm{Dh}}{\mathrm{v}}
$$

where umax is the maximum flow velocity in a channel embedded with a pin fin array and $\mathrm{n}$ is the $\mathbf{v}$ kinematic viscosity of the Flowing fluid. The local and average convective heat transfer coefficients are defined as

$$
\mathrm{hav}=\frac{\mathrm{h}=\frac{\mathrm{q}}{(\mathrm{Tw}-\mathrm{Tf})}}{\left(\mathrm{Tw}_{s} \mathrm{av}-\mathrm{Tf}_{s} \mathrm{av}\right)}
$$

where $\mathrm{q}$ is the heat flux forcing on the heated surface of experiment; $\mathrm{Tw}$ is the local temperature at the end wall surface; Tw,av is the average temperature at the end wall surface; Tf is the local section-averaged temperature of the fluid flow, which is calculated by assuming that it varies linearly along the stream wise direction; and $\mathrm{Tf}$, av is the total average temperature of the fluid flow, which is taken as the arithmetic average of the initial temperature ( Tf,in) and Final temperature(Tf,out). The Exit temperature can be calculated as below using an energy balance across the ends of the test section.

$\mathrm{Tf}$,out $=\mathrm{Tf}$, in $+\frac{(2 \mathrm{q} \text { Aheater })}{\mathrm{mCp}}$

\section{Volume 4 Issue 12, December 2015}




\section{International Journal of Science and Research (IJSR) \\ ISSN (Online): 2319-7064 \\ Index Copernicus Value (2013): 6.14 | Impact Factor (2014): 5.611}

where $\mathrm{m}$ is the flow mass rate, $\mathrm{Cp}$ is the specific heat of the coolant, and Aheater is the heated surface area on each sidewall of tunnel. The local and average Nusselt numbers are distinct based on the hydraulic diameter

The total pressure loss coefficient or friction coefficient is defined as follows

$$
f=\frac{\text { Pin }- \text { Pout }}{(1 / 2) \text { Pu2in }}
$$

where Pin and Pout are the total pressures at the inlet and exit sections, respectively. A specific performance parameter that expect both heat transfer improvement and pressure loss is introduced in

\subsection{Valuation of Heat Transfer}

In order to have a basis for the assessment of the effects of the pin fins, the average Nusselt number (Nus) for the smooth surface (without pin fins) will be correlated as function of Re and Pr as follows:

$\mathrm{N}_{\text {us }}=0.077 \operatorname{Re}^{0.716} \mathrm{P}_{\mathrm{r}}^{1 / 3}$

The Nusselt number based on projected area is connected to the Reynolds number, clearance ratio $(\mathrm{C} / \mathrm{H})$, inter-fin distance ratio (Sy/D) and Prandtl number and is given by the following relation

$\mathrm{N}_{\text {up }}=45.99 \mathrm{Re}^{0.396}(1+\mathrm{C} / \mathrm{H})^{-0.608}(\mathrm{Sy} / \mathrm{D})^{-0.522} \mathrm{P}_{\mathrm{r}}^{1 / 3}$

$\mathrm{N}_{\mathrm{uT}}=6.67 \mathrm{Re}^{0.401}(1+\mathrm{C} / \mathrm{H})^{0.0811}(\mathrm{Sy} / \mathrm{D})^{0.06} \mathrm{P}_{\mathrm{r}}^{1 / 3}$

This equations are legal for the experimental conditions of $13,500 \leq \operatorname{Re} \geq 42,000,1.208<\mathrm{Sy} / \mathrm{D}<3.417,0 \leq \mathrm{C} / \mathrm{H} \leq 1$ and $\mathrm{Pr}=0.7$ by means of this equation the $\mathrm{Nu} / \mathrm{Nus}$ and $\mathrm{Re}$ will be determine for square threaded and helical twisted pin fins and solid fins for different $\mathrm{C} / \mathrm{H}$ ratio i.e. $\mathrm{C} / \mathrm{H}=0$, $\mathrm{C} / \mathrm{H}=0.333, \mathrm{C} / \mathrm{H}=1$ at constant $\mathrm{Sy} / \mathrm{D}=1.208$ and for different $\mathrm{Sy} / \mathrm{D}$ ratios i.e. $\mathrm{Sy} / \mathrm{D}=1.208, \mathrm{Sy} / \mathrm{D}=1.524, \mathrm{Sy} / \mathrm{D}=1.944$, $\mathrm{Sy} / \mathrm{D}=3.417$ at constant $\mathrm{C} / \mathrm{H}=0$. The same will be find out for solid fins and the relative graph between $\mathrm{Nu} / \mathrm{Nus}$ and $\mathrm{Re}$ for square threaded and helical twisted pin fins fins and solid fins is plot.

The $\mathrm{Nu} / \mathrm{Nus}$ based on the projected area, as a function of the duct Reynolds number for the three different pin heights, that is to say $\mathrm{C} / \mathrm{H}=1,0.333$ and 0 at $\mathrm{Sy} / \mathrm{D}=1.208$. It is seen that $\mathrm{Nu} / \mathrm{Nus}$ increases with decreasing $\mathrm{C} / \mathrm{H}$. A decrease in $\mathrm{C} / \mathrm{H}$ means that the height of the fins increases. As the surface area increases with increasing height of the fins, this leads to an increase in $\mathrm{Nu} / \mathrm{Nus}$ characteristics. The Nusselt number that is based on the projected area will reflect the result of the variation in the surface area as well as that of the disturbance in the flow due to square threaded and helical twisted pin fins on the heat transfer. Longer fins can also increase the turbulence of the flow in the channel, consequential in an increase in the heat transfer

The performance of the $\mathrm{Nu} / \mathrm{Nus}$ as a function of the duct Reynolds number and inter-fin distance ratios (Sy/D) for a constant clearance ratio $(\mathrm{C} / \mathrm{H})$ of 0.0 . Decreasing Sy/D means that the fin numbers on the base plate of experiment increases. It is seen from this figure that since the number of fins increases with decreasing Sy/D, which also means an increase in the entire heat transfer area, the heat transfer rate $(\mathrm{Nu} / \mathrm{Nus})$ increases. square threaded and helical twisted pin fins have higher Nusselt number values than solid fins.

\subsection{Valuation of Friction Factor}

The pressure drops in the tunnel with no fins is so small that they could not be deliberate by the pressure transducer. This resulted from smaller length of the test section and smaller roughness of the rectangular duct. The experimental pressure drops over the test section in the finned duct will be calculated under the heated flow circumstances. These measurements will be transformed to the friction factor , $F^{\text {ee }}$

Using the experimental results, $\mathrm{f}$ is associated as a function of the duct Reynolds number, Re, and geometrical parameters. The resulting equation is

$F=2.4 \mathrm{Re}^{-0.0836}(1+\mathrm{C} / \mathrm{H})^{-0.0836}(\mathrm{Sy} / \mathrm{D})^{-0.0814}$

This equation is suitable for $13,500<\operatorname{Re}<42,000,1.208<$ Sy/D $<3.417,0<\mathrm{C} / \mathrm{H}<1$ By using the above equation the variations in the friction factor , $F^{\text {ee }}$ for different clearance ratios $(\mathrm{C} / \mathrm{H})$ i.e. $\mathrm{C} / \mathrm{H}=0, \mathrm{C} / \mathrm{H}=0.333, \mathrm{C} / \mathrm{H}=1$ at constant $\mathrm{Sy} / \mathrm{D}$ $=1.208$ and for different inter-fin space ratios (Sy/D) i.e. $\mathrm{Sy} / \mathrm{D}=1.208, \quad \mathrm{Sy} / \mathrm{D}=1.524, \quad \mathrm{Sy} / \mathrm{D}=1.944, \quad \mathrm{Sy} / \mathrm{D}=3.417$ at constant $\mathrm{C} / \mathrm{H}=0$ is resolute. The same experiment will be approved for the solid fins and friction factor will be find out for the same and the relative graph between $\mathcal{F}$ and $\mathrm{Re}$ for square threaded and helical twisted pin fins and solid fins is plot

It can be seen that the friction factor increases with decreasing $\mathrm{C} / \mathrm{H}$. for the reason that the pin height increases with decreasing $\mathrm{C} / \mathrm{H}$, the by-pass area over the fin tips decreases. Thus, resistance against to the flow increases.

The other notable result is seen for the friction factor. The friction factor values are approximately independent of the Reynolds number and each $\mathrm{C} / \mathrm{H}$ value. It is emphasized in a different optimization study for a finned heat exchanger that interestingly, stream wise distance between fins is more efficient parameter on the friction factor than span wise distances. On the other hand, as the resistance to the flow will be lesser due to the helical path, friction factor is lower for the square threaded and helical twisted pin fins than the solid fins.

\subsection{Enhancement of Efficiency}

The enhancement efficiency of the experiment for heat transfer technique can be expressed as

$$
\eta=\frac{h a}{h s}
$$

where "ha" and "hs" are the convective heat transfer coefficient with and without pin fins, correspondingly the following equation can be written for the heat transfer efficiency for the pin fins according to total heat transfer surface area

$\eta=\frac{h a}{h s}=51.09 \mathrm{Re}^{-0.358}(1+\mathrm{C} / \mathrm{H})^{0.1028}(\mathrm{Sy} / \mathrm{D})^{0.0812}$

By means of this equation the effect of the inter-fin distance on heat transfers improvement efficiency for different interfin space ratios (Sy/D) i.e. $\mathrm{Sy} / \mathrm{D}=1.208, \mathrm{Sy} / \mathrm{D}=1.524$, 


\section{International Journal of Science and Research (IJSR) \\ ISSN (Online): 2319-7064 \\ Index Copernicus Value (2013): 6.14 | Impact Factor (2014): 5.611}

$\mathrm{Sy} / \mathrm{D}=1.944, \mathrm{Sy} / \mathrm{D}=3.417$ at constant $\mathrm{C} / \mathrm{H}=0$ will be determine and graph is plot similarly the effect of the clearance ratio on improvement efficiency for different clearance ratio $(\mathrm{C} / \mathrm{H})$ ) i.e. $\mathrm{C} / \mathrm{H}=0, \mathrm{C} / \mathrm{H}=0.333, \mathrm{C} / \mathrm{H}=1$ at constant $\mathrm{Sy} / \mathrm{D}=1.208$ will be determine and graph is plot.

The heat transfer improvement efficiencies are plot. It shows the effect of the clearance ratio on improvement efficiency $(\eta)$ while other show the effect of the inter-fin distance ratio on enhancement efficiency( $\eta)$. For a net energy gain, the value of the $(\eta)$ must be larger than unity. In other words, for an effective heat transfer improvement technique, it must have values greater than unity.it is apparent that as the Reynolds number increases, the enhancement efficiency decreases for both the inter-fin spacing ratio and clearance ratio. Experiment show that the heat transfer enhancement efficiency decreases with increasing Sy/D and $\mathrm{C} / \mathrm{H}$. In other words:

(1)The heat transfer enhancement efficiencies are higher than unity for all investigated conditions of the project. This means that the use of pin fins leads to an benefit on the basis of heat transfer enhancement. (2) Higher numbers of pin fins and longer pin fins have improved performance. In other words, for higher thermal performance, a lower inter-fin distance ratio and clearance ratio should be favored. (3) At a lower Reynolds number, the rectangular channels with pin fin arrays give higher performance than those at a higher Reynolds number.

\section{Conclusion}

The present review paper help to can be concluded that lot of work has been carried out to investigate the effect of different geometries of pin fin with inline and staggered arrangement and sizes of pin fin on heat transfer and friction factor. considerable enhancement in the heat transfer can be achieved with little change of its geometry as helical twisted and square thread profiles as it leads to increase in the cross sectional area and turbulence. The effects of the flow and geometrical parameters on the heat transfer and friction characteristics can be determined. Various investigators have developed correlations for heat transfer and friction factor for pin fin in a rectangular channel ducts having different geometries. These correlations can be used to predict the thermal performance as well as pressure drops of square threaded and helical twisted pin fins across the rectangular tunnel.

\section{Acknowledgement}

The authors gratefully acknowledge the valuable support received from the Marathwada Institute of Technology Aurangabad Maharashtra, India for this project.

\section{References}

[1] Fluid flow characteristics for shell side of double-pipe heat exchanger with helical fins and pin fins L Zhang, W Du, J Wu, Y Li, Y Xing - ... Thermal and Fluid Science, 2012 - Elsevier

[2] Bayram Sahin, Alparslan Demir Performance analysis of a heat exchanger having perforated square fins, ELSEVIER, Applied Thermal Engineering 28 (2008) 621-632

[3] Thermal performances of enhanced smooth and spiky twisted tapes for laminar and turbulent tubular flows SW Chang, MH Guo - International Journal of Heat and Mass Transfer, 2012 - Elsevier

[4] R. Karthikeyan* et al. / (IJAEST) International Journal of Advanced Engineering Science And Technology Vol No. 10, Issue No. 1, 125 - 138

[5] Tzer-Ming Jeng,Sheng-Chungzeng, ELSEVIER, International Journal of Heat and Mass Transfer 50 (2007) 2364-2375

[6] Giovanni Tanda,PERGAMON, International Journal of Heat and Mass Transfer 44 (2001) 3529-3541

[7] G.J. Vanfossen and B.A. Brigham Length to diameter ratio and row number effects in short pin fin heat transfer, ASME J. Eng. Gas Turbines Power 106 (1984) 241-244.

[8] D.E. Metzger, C.S. Fan, S.W. Haley, Effects of pin shape and array orientation on heat transfer and pressure loss in pin fin arrays, J. Eng. Gas Turbines Power 106 (1984) 252-257.

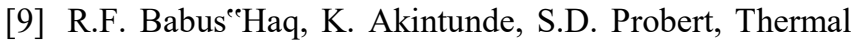
performance of a pin-fin assembly, Int. J. Heat Fluid Flow 16 (1995) 50-55.

[10] O.N. Sara, T. Pekdemir, S. Yapici, M. Y1lmaz, Heattransfer enhancement in a channel flow with perforated rectangular blocks, Int. J. Heat Fluid Fl. 22, 509-518.

[11] Influence of spiky twisted tape insert on thermal fluid performances of tubular air-water bubbly flow SW Chang, AW Lees, HT Chang International Journal of Thermal ..., 2009 - Elsevier

[12] A comparative review of self-rotating and stationary twisted tape inserts in heat exchanger C Zhang, D Wang, K Ren, Y Han, Y Zhu, X Peng... - ... and Sustainable Energy ..., 2016 - Elsevier

[13] Investigation on flow and heat transfer characteristics in rectangular channel with drop-shaped pin fins www.sciencedirect.com/science/article/pii/S2212540X1 2000041 Pg. No. : 66-68

[14]P. K. Nag, 2006, "Heat \& Mass Transfer", $2^{\text {nd }}$ Edition, Tata McGraw Hill Co. Pg. No. : 86-108 \& 425-449

[15] J. P. Holman, 2004, "Heat Transfer", 9thEdition, Tata McGraw Hill Co,” Pg. No. 43-53\& 315-350

[16] Yunus A. Çengel, 2004, "Heat Transfer- A Practical Approach", SI units 2nd Edition, Tata McGraw Hill Co., Pg. No. : 156-168, 333-352\& 459-500

[17] Sparrow EM, Ramsey JW. Heat transfer and pressure drop for a staggered wall-attached array of cylinders with tip clearance. Int J Heat Mass Transfer 1978;21:1369-77.

[18] Sparrow EM, Ramsey JW, Altemani CAC. Experiments on in-line pin fin arrays and performance comparison with staggered arrays. ASME J Heat Transfer 1980;102:44-50.

[19] Sparrow EM, Samie F. Heat transfer and pressure drop results for one-and two-row arrays of finned tubes. Int $\mathrm{J}$ Heat Mass Transfer 1985;28:2247-59.

[20] Simoneau RJ, Vanfossen GJ. Effect of location in an array on heat transfer to a short cylinder in crossflow. ASME J Heat Transfer 1984;106:42-8.

[21] Matsumoto R, Kikkawa S, Senda M. Effect of pin fin 


\section{International Journal of Science and Research (IJSR) \\ ISSN (Online): 2319-7064 \\ Index Copernicus Value (2013): 6.14 | Impact Factor (2014): 5.611}

arrangement on endwall heat transfer. JSME Int $\mathrm{J}$ 1997;40(Series B):142-51.

[22] Armstrong J, Winstanley D. A review of staggered array pin fin heat transfer for turbine cooling applications.ASME J Turbomach 1988;110:94-103.

[23] T.M. Jeng, S.C. Tzeng, A semi-empirical model for estimating permeability and inertial coefficient of pinfin heat sinks, Int. J. HeatMass Transfer 48 (2005) 3140-3150.

[24] S. Okamoto, K. Tsunoda, T. Katsumata, N. Abe, M. Kijima, Turbulent near-wakes of periodic array of square blocks on a plate, Int. J. Heat Fluid Fl. 17 (3) (1996) 211-218.

[25] A. Zukauskas, R. Ulinskas, Efficiency parameters for heat transfer in tube banks, Heat Transfer Eng. 6 (1985) $19-25$.

[26]B.A. Jubran, M.A. Hamdan, R.M. Abdualh, Enhanced heat transfer, missing pin, and optimization for cylindrical pin fin arrays, ASME J. Heat Transfer 115 (1993) 576-583.

[27] M.A. Tahat, R.F. Babus ${ }^{e} H a q$, S.D. Probert, Forced steady-state convections from pin-fin arrays, Appl. Energy 48 (1994) 335-351.

[28] M. Tahat, Z.H. Kodah, B.A. Jarrah, S.D. Probert, Heat transfer from pin-fin arrays experiencing forced convection, Appl. Energy 67 (2000)

[29] R.F. Babus 'Haq, K. Akintunde, S.D. Probert, Thermal performance of a pin-fin assembly, Int. J. Heat Fluid Flow 16 (1995) 50-55. 419-442.

[30] V.B. Grannis, E.M. Sparrow, Numerical simulation of fluid flow through an array of diamond-shaped pin fins, Numer. Heat Transfer (Part A) 19 (1991) 381-403.

[31] H.I. You, C.H. Chang, Determination of flow properties in non- Darcian flow, ASME J. Heat Transfer 119 (1997) 190-192.

[32]H.I. You, C.H. Chang, Numerical prediction of heat transfer coefficient for a pin-fin channel flow, ASME J. Heat Transfer 119 (1997) 840-843.

[33] S.Y. Kim, A.V. Kuznetsov, Optimization of pin-fin heat sinks using anisotropic local thermal nonequilibrium porous model in a jet impinging channel, Numer. Heat Transfer (Part A) 44 (2003) 771-787.

[34]D. Kim, S.J. Kim, A. Ortega, Compact modeling of fluid flow and heat transfer in pin fin heat sinks, ASME J. Electron. Packaging 126 (2004) 342-350.

[35] A.K. Saha, S. Acharya, Unsteady simulation of turbulent flow and heat transfer in a channel with periodic array of cubic pin-fins, Numer. Heat Transfer (Part A) 46 (2004) 731-763.

[36] O.N. Sara, S. Yapici, M. Yilmaz, T. Pekdemir, Second law analysis of rectangular channels with square pinfins, Int. Commun. Heat Mass Transfer 28 (2001) 617630.

[37] O.N. Sara, Performance analysis of rectangular ducts with staggered square pin fins, Energy Convers. Manage. 44 (2003) 1787-1803.

[38] Jinn Foo and Chee Seng Tan (2012) Heat transfer enhancement with perforated fin fins subject to impinging flow, International Journal of mechanical computational and manufacturing research, 1, pp. 5661.

[39]S. Chamoli, R. Chauhan, N.S.Thakur, , (2011) Numerical analysis of heat transfer and thermal performance analysis of surface with circular profile fins, International journal of energy science, 1, pp. 1118.

[40]M. Baruah, A. Dewan and P. Mahanta, (2011) Performance of elliptical pin fin heat exchanger with three elliptical perforations, CFD letters, 3, pp. 65-73

[41] Wadhah Hussein Abdul Razzaq AI-Doori, (2011) Enhancement of natural convection heat transfer from the rectangular fins by circular perforations, International journal of automotive and mechanical engineering, 4, , pp. 428-436

[42] M. Baruah, A. Dewan and P. Mahanta, (2011) Performance of elliptical pin fin heat exchanger with three elliptical perforations, CFD letters, 3, pp. 65-73

[43] Wadhah Hussein Abdul Razzaq AI-Doori, (2011) Enhancement of natural convection heat transfer from the rectangular fins by circular perforations, International journal of automotive and mechanical engineering, 4, , pp. 428-436

[44] ANSYSInc.,ANSYSFluentv12.0 SoftwareUser"sGide, Lebanon, NH,2009.

\section{Volume 4 Issue 12, December 2015}

